Edith Cowan University

Research Online

Research outputs 2014 to 2021

4-2017

\title{
A nurse-led education and cognitive behaviour therapy-based intervention among adults with uncontrolled type 2 diabetes: A randomised controlled trial
}

\author{
Lisa Whitehead \\ Edith Cowan University \\ Marie T. Crowe \\ Janet D. Carter \\ Virginia R. Maskill \\ David Carlyle
}

See next page for additional authors

Follow this and additional works at: https://ro.ecu.edu.au/ecuworkspost2013

Part of the Investigative Techniques Commons

10.1111/jep.12725

Whitehead, L. C., Crowe, M. T., Carter, J. D., Maskill, V. R., Carlyle, D., Bugge, C., \& Frampton, C. (2017). A nurse-led education and cognitive behaviour therapy-based intervention among adults with uncontrolled type 2 diabetes: $A$ randomised controlled trial. Journal of Evaluation in Clinical Practice. https://doi.org/10.1111/jep.12725

This Journal Article is posted at Research Online.

https://ro.ecu.edu.au/ecuworkspost2013/2565 


\section{Authors}

Lisa Whitehead, Marie T. Crowe, Janet D. Carter, Virginia R. Maskill, David Carlyle, Carol Bugge, and Chris M.A Frampton

This journal article is available at Research Online: https://ro.ecu.edu.au/ecuworkspost2013/2565 


\title{
A nurse-led education and cognitive behaviour therapy-based intervention among adults with uncontrolled type 2 diabetes: $A$ randomised controlled trial
}

\author{
Lisa C. Whitehead $\mathrm{PhD}^{1}$ (1) । Marie T. Crowe $\mathrm{PhD}^{2}$ | Janet D. Carter $\mathrm{PhD}^{3}$ । \\ Virginia R. Maskill MHealSc ${ }^{4}$ | Dave Carlyle $\mathrm{PhD}^{5}$ | Carol Bugge $\mathrm{PhD}^{6}$ | \\ Chris M. A. Frampton $\mathrm{PhD}^{7}$
}

${ }^{1}$ Associate Dean Research, School of Nursing and Midwifery, Edith Cowan University, Joondalup, Australia

${ }^{2}$ Associate Dean, Centre for Postgraduate Nursing Studies \& Department of

Psychological Medicine, University of Otago, Christchurch, New Zealand

${ }^{3}$ Head of Department, Department of Psychology, University of Canterbury, Christchurch, New Zealand

${ }^{4}$ Lecturer, Centre for Postgraduate Nursing Studies, University of Otago, Christchurch, New Zealand

${ }^{5}$ Senior Lecturer, School of Health Sciences, University of Otago, Christchurch, New Zealand

${ }^{6}$ Senior Lecturer, School of Health Sciences, University of Stirling, Stirling, UK

${ }^{7}$ Biostatistician, Department of Psychological Medicine, University of Otago, Christchurch, New Zealand

\section{Correspondence}

Lisa C. Whitehead, School of Nursing and Midwifery, Edith Cowan University, 270

Joondalup Drive, Joondalup, Western

Australia, Australia.

Email: I.whitehead@ecu.edu.au

\begin{abstract}
Rationale, aims and objectives Diabetes mellitus is associated with significant morbidity, mortality, and escalating health care costs. Research has consistently demonstrated the importance of glycaemic control in delaying the onset, and decreasing the incidence, of both the short-term and long-term complications of diabetes. Although glycaemic control is difficult to achieve and challenging to maintain, it is key to reducing negative disease outcomes.

The aim of this study was to determine whether a nurse-led educational intervention alone or a nurse-led intervention using education and acceptance and commitment therapy (ACT) was effective in reducing hemoglobin $A_{1 c}\left(\mathrm{HbA}_{1 c}\right)$ in people living with uncontrolled type 2 diabetes compared to usual care.
\end{abstract}

Methods Adults over the age of 18 years, with a confirmed diagnosis of type 2 diabetes and $\mathrm{HbA}_{1 \mathrm{c}}$ outside of the recommended range $(4 \%-7 \%, 20-53 \mathrm{mmol} / \mathrm{mol})$ for 12 months or more, were eligible to participate. Participants were randomised to either a nurse-led education intervention, a nurse-led education plus ACT intervention, or a usual care. One hundred and eighteen participants completed baseline data collection $(\mathrm{N}=34$ education group, $\mathrm{N}=39$ education plus $\mathrm{ACT}, \mathrm{N}=45$ control group). An intention to treat analysis was used.

Results A statistically significant reduction in $\mathrm{HbA}_{1 \mathrm{c}}$ in the education intervention group was found $\left(P=.011[7.48,8.14]\right.$ ). At 6 months, $\mathrm{HbA}_{1 \mathrm{c}}$ was reduced in both intervention groups (education group -0.21 and education and ACT group -0.04) and increased in the control group (+0.32). A positive change in $\mathrm{HbA}_{1 \mathrm{c}}\left(\mathrm{HbA}_{1 \mathrm{c}}\right.$ reduced) was noted in 50 participants overall. Twice as many participants in the intervention groups demonstrated an improvement as compared to the control group ( $56 \%$ of the education group, $51 \%$ education plus ACT, and $24 \%$ control group.

Conclusions At 6 months post intervention, $\mathrm{HbA}_{1 \mathrm{c}}$ was reduced in both intervention groups with a greater reduction noted in the nurse-led education intervention.

\section{KEYWORDS}

nursing, randomised controlled trial, type 2 diabetes mellitus

\section{1 | INTRODUCTION}

Daily management of diabetes is essential in controlling blood glucose, however, many people living with diabetes are unable to maintain glycaemic control within the recommended levels (4\%-7\%,
20-53 mmol/mol). ${ }^{1}$ Diet, exercise, stress, and medication management are the key mediators of glycaemic control ${ }^{2}$ and areas strongly influenced by self-management through individual behaviour and action. ${ }^{3}$ The short-term and long-term effects of hyperglycaemia are multiple, including microvascular changes (eg, retinopathy, nephropathy, and 
neuropathy) and macrovascular (eg heart disease)., ${ }^{4,5}$ Uncertainty does remain around the extrapolation of population-based risk reduction estimations to individual predictions, ${ }^{6}$ where evidence relating to glycaemic control and long-term outcomes have been established through large prospective cohorts. Further, tight glycaemic control can result in harmful effects, for example an increase in hypoglycaemic events. $^{7}$

In addition to a global guideline on diabetes management, ${ }^{8}$ evidence-based guidelines exist across many countries on the treatment of type 2 diabetes (eg, in another reference ${ }^{2}$ ) with a consistent focus on patient education, dietary advice, managing cardiovascular risk, managing blood glucose levels, and managing the risk of long-term complications. Optimal management, however, is only thought to be reaching the minority ${ }^{8}$ with reasons such as the size and complexity of the evidence base, the complexity of diabetes care itself, a lack of proven cost-effective resources for diabetes care, and diversity in standards of clinical practice cited as driving disparities in clinical care.

The evidence on interventions to support self-management for people with long-term conditions is large and attempts to draw together individual study findings to clarify what works, for whom, and in what contexts are available (eg, in the work of Taylor et $\mathrm{al}^{9}$ ). Interventions directly related to improving the self-management of glycaemic control can be broadly categorised into individual and group-based interventions, educational and behavioural interventions, with fewer interventions combining the latter 2 elements. ${ }^{10} \mathrm{~A}$ review of all self-management programmes or multicomponent interventions aimed at self-management; education, both group based and individual; behavioural or counselling interventions; and social support for people living with type 2 diabetes $^{9}$ reported good evidence that selfmanagement support improves blood glucose control in the shortterm, with a reduction in mean difference of around $0.4 \%$. The effectiveness of interventions longer term was not as strong, although this was attributed to fewer studies reporting data at 12 months and beyond. The impact of self-management interventions on individuals' quality of life and their psychological well-being was not supported, although equally, interventions did not have a detrimental effect. The meta-review was not able to pin point effective elements across interventions, instead suggesting that self-management support may be delivered in many ways, by different professionals and lay people, and that in light of the large number of randomised controlled trials and reviews included within the meta-review the failure to reach any conclusion on the optimal model of delivery could reflect that there is no one way. ${ }^{9}$ The authors suggest that multiple models of delivery may be equally effective, and consideration may instead need to be given to other factors that may influence effectiveness, such as the real-world context.

Reviews with a less diverse focus have made recommendations relating to effective elements of interventions. In relation to interventions for women of African/Caribbean and Hispanic/Latin ethnicity living in industrialised countries, 5 intervention features (hospitalbased intervention setting; group intervention format; situational problem-solving; high intensity, 10 or more sessions; and incorporating dieticians as interventionalists) were found to have a broad impact on the majority of outcomes assessed (diet, anthropometrics, physical activity, and hemoglobin $A_{1 c}\left[H_{b A_{1 c}}\right]$ ). A review of behavioural interventions (Health Quality ${ }^{11}$ ), found that the interventions with the largest effects were those with higher baseline $\mathrm{HbA}_{1 \mathrm{c}}(\geq 9 \%)$ and in which the interventions were of at least 1 year in duration. A review and meta-analysis ${ }^{10}$ on motivational interventions in the management of $\mathrm{HbA}_{1 \mathrm{c}}$ noted that the small number of studies and issues of heterogeneity indicated the need for caution in interpreting the findings, and the contribution of motivational interventions may be better assessed by outcomes such as behaviour change.

The current study aimed to contribute to the evidence on the effectiveness of motivational interventions and the interrelation between self-management behaviours and glycaemic control. Acceptance and commitment therapy (ACT) is a form of cognitive behavioural therapy. The premise of ACT is the existence of a constant interplay between the internal and external environment affecting the individual's overall functioning. ${ }^{12}$ Overt behaviour (actions), cognitions (thoughts, beliefs, and perceptions), feelings, and physiology are closely and interactively integrated, and could therefore impact the way in which a patient manages his or her diabetes overall. Acceptance and commitment therapy can take a holistic approach to diabetes management including addressing psychological and motivational barriers, acceptance of elements of management, and focuses patients on moving in the direction of their values. ${ }^{13}$

A previous study comparing an ACT and education intervention with an education only intervention ${ }^{13}$ found a significant improvement in $\mathrm{HbA}_{1 \mathrm{c}}$ and in acceptance of diabetes (attitudes and values) and selfmanagement skills for those completing the ACT plus education intervention. Building on this work, it was hypothesised that for people with long-term hyperglycaemia, ACT could raise participants' awareness of the interaction between cognitions, feelings, and behaviour and so enable people to better self-manage, leading to improved glycaemic control. The objective of this study was to determine whether a nurse-led educational intervention alone or a nurse-led intervention using education and ACT were effective in reducing $\mathrm{HbA}_{1 \mathrm{c}}$ in people living with uncontrolled type 2 diabetes compared to usual care.

\section{I METHODS}

\section{1 | Study design}

The design was a 3 arm parallel group randomised controlled trial comparing 2 active treatment groups with a control condition. This design was chosen over a factorial design (education alone versus ACT alone versus education and ACT versus neither) on the premise that a certain level of diabetes knowledge would be essential for individuals to use the strategies developed through the ACT intervention. The half day education intervention aimed to provide all participants in the group with the same level of knowledge to apply the ACT strategies.

Three pairwise comparisons were planned for the analysis of outcomes (education versus control, education plus ACT versus control, and education versus education plus ACT). A total of 32 participants were required in each group to achieve $80 \%$ power to detect as statistically significant (2-tailed $a=0.05)$ an absolute difference between groups at 6 months in $\mathrm{HbA}_{1 \mathrm{c}}$ levels of $0.5 \%$, assuming an SD of $0.7 \%$. The choice of effect size for power analyses was based on data 
from the United Kingdom Prospective Diabetes Study ${ }^{14}$ with a $0.5 \%$ difference in $\mathrm{HbA}_{1 \mathrm{c}}$ levels regarded as being clinically significant. The same effect size was chosen for both interventions based on the assumption that a reduction in $\mathrm{HbA}_{1 \mathrm{c}}$ of the same magnitude would be as clinically significant for both groups. The study was granted ethical approval from the Upper South B Regional Ethics Committee, New Zealand, reference number URB/09/08/039.

\section{2 | Recruitment}

The inclusion criteria were a clinical diagnosis of type 2 diabetes for 12 months or more, age 18 years and over, and persistent, suboptimal glycaemic control. This was defined as $\mathrm{HbA}_{1 \mathrm{c}}>7 \%, 53 \mathrm{mmol} / \mathrm{mol}$ in the past 12-18 months, with at least 2 records of $\mathrm{HbA}_{1 \mathrm{c}}>7 \%$, $53 \mathrm{mmol} / \mathrm{mol}$, during this period and $\mathrm{HbA} 1 \mathrm{c}>7 \%, 53 \mathrm{mmol} / \mathrm{mol}$ on recruitment. Exclusion criteria were non-English speaking, pregnancy, short-term or serious medical conditions, and currently in psychotherapy or participation in a diabetes education programme in the past 12 months. Following ethical approval, a range of recruitment avenues were used including radio advertisements, adverts in community news letters, and newspapers and letters sent to patients who met the study criteria through medical centres, across 1 city in New Zealand. Those people who contacted the research assistant as interested in participation were sent a study information sheet, a consent to be contacted form, and a stamp addressed envelope. All those who returned a consent to be contacted form were called by the research assistant to confirm inclusion eligibility, and written consent was gained to participate in the study and for the research assistant to contact the medical centre at which they were registered to obtain $\mathrm{HbA}_{1 \mathrm{c}}$ results.

Permuted block randomisation using a computer-generated randomisation sequence with a block size of 24 allowed for timely randomisation of participants, where recruitment took place across a 12-month period. A biostatistician completed the randomised allocation. The biostatistician was independent from all other study procedures. The biostatistician sent information on the allocation to the research assistant. Data were collected at baseline, 3 months following baseline and 6 months following baseline. All study questionnaires were sent by post together with a prepaid envelope for return.

\subsection{Description of the interventions}

The decision to run the intervention on 1 day was pragmatic. The intention was to make the intervention as cost effective and convenient as possible for participants and looking to the future, for providers who may wish to take up the intervention in practice.

Both workshops consisted of a 1 day workshop held at a central city location. The workshop ran from 10AM to 5.30PM with a 1 hour lunch break. The interventions were developed by the research team, primary care nurses, and an advisory group. The main content was based on the topic areas deemed to be important cross 3 diabetes education programmes. ${ }^{12,13,15}$ The research team included experienced educators and clinicians who developed a format for delivery that were felt to promote engagement in learning and discussion and included visual learning and active exercises, such food labelling. The interventions were developed into work books for the participants and a
PowerPoint slide presentation for the presenters. The package was reviewed by the advisory group, who included a consumer, clinicians, and Maori and Pacific Island advisors. Both interventions were piloted with a small group of volunteers who were diagnosed with type 2 diabetes but who had experienced hyperglycaemia for just less than 1 year and so did not fully meet the study criteria. Feedback on the content and delivery from the participants and the nurses were incorporated. Changes were minimal and related to using 1 diagram over another, for example, rather than changes to the topics covered.

\subsection{The education intervention}

The education intervention sessions were run by 2 primary health care based nurses who were trained in the delivery of the intervention by 2 of the study investigators. The education intervention covered the topics of the basic pathophysiology of diabetes, understanding diabetes and glucose, understanding the risk factors and complications associated with diabetes, food groups, portion sizes, self-management of diabetes through diet, exercise, medication, and stress management, monitoring diabetes, including awareness of hypo and hyperglycaemia, and when to seek help. Underpinning the content were the themes of increasing understanding, how to take control and planning for the future. The intended changes related to increasing understanding of diabetes, satisfaction with diabetes management, an increase in selfmanagement activities, and maintenance or improvement of mental health, as measured through anxiety and depression.

\subsection{The education plus ACT intervention}

In the education plus ACT intervention, time was divided equally between the education intervention and the ACT intervention to maintain the same amount of contact time between participants and the nurses. Participants received the same content in education but did not have the opportunity to discuss the material in as much depth as the education only group nor spend as much time on self-directed exercises in the handbook during the workshop. The ACT component addressed mindfulness and acceptance training in relation to difficult thoughts and feelings about diabetes, exploration of personal values related to diabetes, and a focus on the ability to act in a valued direction while contacting difficult experiences. The ACT component drew on material developed in a previous study. ${ }^{13}$ The workshop was led by a mental health nurse with expertise in ACT who received supervision from a clinical psychologist. The education component was delivered by one of the nurses providing the education intervention.

The intended changes related to increased acceptance of diabetesrelated thoughts and feelings and a reduction in the extent to which thoughts and feelings interfere with valued action, increase in understanding of diabetes, satisfaction with diabetes management, an increase in self-management activities, and maintenance or improvement of mental health, as measured through anxiety and depression.

\section{6 | Fidelity}

The fidelity of the intervention was enhanced through the development of a manual for both interventions; all sessions were recorded and reviewed by $\mathrm{LW}$ and $\mathrm{JC}$ for adherence to the protocol and 
manuals, and 1 nurse participated in all of the intervention sessions to enhance continuity of style and content of the sessions.

\section{7 | Control group}

The control groups were mailed the questionnaires at the same time points as the 2 intervention groups. Participants in the control group continued to receive routine diabetes care. Routine care generally comprised visits to the GP/practice nurse as initiated by the patient with an annual invitation by the practice to attend for a health check involving measurement of $\mathrm{HbA}_{1 \mathrm{c}}$ (goal $\leq 7 \%$ ), weight, blood pressure (goal 13/80), total cholesterol (goal $\leq 4$ ), HDL cholesterol (goal $\geq 1$ ), LDL cholesterol (goal $<2$ ), triglycerides (goal $<1.7$ ), microalbuminuria (ratio < 3), date of last eye examination (at least every 2 years), foot check, and sensation and pulses. The control groups were not offered the opportunity to participate in an intervention posttrial.

\section{8 | Outcome measures}

The primary outcome variable was glycaemic control $\left(\mathrm{HbA}_{1 \mathrm{c}}\right)$. The secondary outcome variables were acceptance of diabetes-related thoughts and feelings and extent to which thoughts and feelings interfere with valued action, increase in understanding of diabetes, satisfaction with diabetes management, an increase in self-management activities, and maintenance or improvement of mental health, as measured through anxiety and depression.

\section{9 | Glycaemic control}

$\mathrm{HbA}_{1 \mathrm{c}}$ was analysed by a local medical laboratory. Participants were asked to either visit their local medical laboratory, widely distributed throughout the city, or if required a mobile phlebotomist who took the sample at the participant's home. The phlebotomist was blinded to the group allocation of participants. Time points for measurement were at baseline, 3 months and 6 months. A 2-week window was allowed around the designated data collection time points.

The questionnaires were self-administered. They were sent to the participant's postal address and returned in a stamp addressed envelope. The pack contained information on who to contact if assistance was required (the research assistant), however, no one made contact for support to complete the questionnaires.

\subsection{1 | Acceptance of diabetes}

The Acceptance and Action Diabetes Questionnaire (AADQ) ${ }^{13}$ is an 11 item Likert type scale to measure acceptance of diabetes-related thoughts and feelings and the extent to which they interfere with valued action (eg, I avoid thinking about what diabetes can do to $\mathrm{me}$ ). The scale has demonstrated good inter-rater reliability (Cronbach $a=$.94). Scores range from 11 to 55 with a higher score reflecting greater nonacceptance.

\subsection{2 | Anxiety and depression}

Anxiety and depression were measured through the Hospital Anxiety and Depression Scale (HADS). ${ }^{16}$ The HADS has been used extensively in research and has been shown to have good validity, specificity and sensitivity, ${ }^{17}$ and good test-retest reliability. ${ }^{18}$ Although the HADS is a screening tool, it correlates well with clinical assessments of anxiety and depression. A score is generated for anxiety and depression, both ranging from 0 to 21 with a score of 0-7 indicating subclinical symptoms, 8-10 possible clinical levels and a score of 11 or over probable clinical levels.

\subsection{3 | Understanding of the management of diabetes}

Understanding of the management of diabetes was assessed by a subscale of the Diabetes Care Profile (Cronbach $a=.60-.95) .{ }^{19}$ The Diabetes Care Profile comprises 14 subscales in total. The understanding subscale comprises 10 items and explores understanding of key aspects of the management of diabetes, eg, "How do you rate your understanding of diet and blood sugar control?" Reliability was explored in 2 large studies, a community study $(n=440)$ and medical centre study ( $n=352$ ). Reliabilities (Cronbach alpha) of the understanding subscale were reported as .92 and .92 respectively. ${ }^{19}$ Scores range from 10 to 50 , with a higher score indicating better self-rated understanding of diabetes.

\subsection{4 | Diabetes treatment satisfaction}

The Diabetes Treatment Satisfaction Questionnaire (DTSQ) ${ }^{20}$ was used to measure satisfaction with diabetes treatment. The 6 item scale assesses treatment satisfaction and 2 items assess perceived frequency of hyperglycaemia and hypoglycaemia. Ceiling effects have been noted with the DTSQ and the DTSQ change (DTSQc) was developed to overcome these. ${ }^{21}$ The authors recommend using the DTSQ first to anchor the findings, followed the DTSQc to explore how people's satisfactions with perceived hypoglyacaemia and hyperglycaemia have changed. The DTSQ has been widely used and is recommended by the World Health Organisation and the International Diabetes Federation as useful in assessing outcomes of diabetes care. ${ }^{22}$ On the DTSQ, each of the 8 items are scored on a scale of 0-6 with a higher score indicating greater satisfaction. For the DTSQc, each item is scored on a scale of -3 to +3 with a higher score indicating greater satisfaction.

\subsection{5 | Diabetes self-care activities}

The summary of diabetes self-care activities measure was used to assess self-care activity. ${ }^{23}$ Three of the 8 subscales; general diet, exercise, and blood glucose testing were used in this study. The inter-rater reliability, measured by means of the Cronbach alpha coefficient, ranged from 0.66 to 0.80 for the 3 subscales independently ${ }^{24,25}$ and a Cronbach alpha of 0.71 for the 3 subscales collectively as measured using all baseline data from this study.

The subscale general diet includes 2 questions: How many of the last 7 days have you followed a healthy eating plan? And over the past month, how many days/week have you followed your eating plan? The exercise component questions on how many of the last 7 days did you participate in at least 30 minutes of physical activity? On how many of the last 7 days did you participate in a specific exercise session other than what you do around the house/work? And the blood glucose subscale, on how many of the last 7 days did you test your blood sugar? and On how many of the last 7 days did you test your blood sugar the recommended number of times? The derived scores reflect the number of days within a week recommended activity related to diet, 
exercise, and blood glucose monitoring have been followed. The range is $0-42$, with a higher score reflecting greater self-management.

\subsection{6 | Data analysis}

Statistical analyses were performed using the Statistical Package for the Social Sciences, version 19 (Statistical Package for the Social Sciences In, Chicago, Illinois). Standard descriptive statistics were used to summarise demographic and clinical characteristics for the randomised groups. Analyses were conducted on an intention-to-treat basis, which included all participants who completed the baseline questionnaires, a blood test for $\mathrm{HbA}_{1 \mathrm{c}}$ and in the intervention groups, who attended the workshop. Missing values were handled according to the guidelines for each scale. An analysis of covariance (ANCOVA) was used to compare the $\mathrm{HbA}_{1 \mathrm{c}}$ levels at 6 months between randomised groups where the randomised group was treated as a fixed factor and the baseline value for $\mathrm{HbA}_{1 \mathrm{c}}$ (taken within 3 months of commencing the study) as a covariate. If a significant effect $(P<.05)$ of randomised group was identified from the ANCOVA, then pairwise comparisons of each intervention group with the usual care were undertaken. The ANCOVA was also used to compare the secondary outcomes using randomised group as a fixed factor and the relevant baseline level as a covariate.

\subsection{0 | Results}

\subsection{1 | Recruitment outcomes and sample description}

Over a 12-month period, 303 people responded and following assessment for eligibility; 172 people who met the study criteria were approached. One hundred and fifty seven participants with glycaemic control outside of the recommended range for over 12 months gave informed consent and were randomised to one of 3 groups, education, education plus ACT, or usual care (control). In total, 51 participants were randomised to the education only intervention, 54 to the education plus ACT intervention, and 52 to the control group. A total of 34 participants declined to participate postrandomisation; 14 participants had moved away or were no longer contactable, and 25 participants had changed their minds, mostly related to lack of time.

The differences in baseline characteristics across the 3 randomised groups were not significantly different (Table 1 ).
At 6 months, 21 people did not complete a blood test for $\mathrm{HbA}_{1 \mathrm{c}}$ level and 12 participants did not complete and return the questionnaires. Baseline analysis found no difference between those lost to follow up and those who completed the study. Intention to treat analysis was conducted. Figure 1 outlines the trial profile.

\subsection{2 | Effects on glycaemic control}

At 6 months, $\mathrm{HbA}_{1 \mathrm{c}}$ was reduced in both intervention groups (Education group -.21, education plus ACT group -.04) and increased in the control group (+.32). The primary outcome results are presented in Tables 2, 3.

An ANCOVA using $\mathrm{HbA}_{1 \mathrm{c}}$ prescores as the covariate found significant differences between the participants' $\mathrm{HbA}_{1 \mathrm{c}}$ at 6 months $(F(2,114)=3.29, P=.04)$. Planned contrasts found no statistical difference in $\mathrm{HbA}_{1 \mathrm{c}}$ at 6 months between the control group and the education plus ACT group $(P=.079[7.61,8.23])$. The mean difference in $\mathrm{HbA}_{1 \mathrm{c}}$ between the control group and education intervention group at 6 months was statistically significant $(P=.011[7.48,8.14])$. Exploring change in $\mathrm{HbA}_{1 \mathrm{c}}$ by direction (positive, none, or negative) showed that, proportionally, twice as many participants in the intervention groups demonstrated a reduction in $\mathrm{HbA}_{1 \mathrm{c}}$ compared to the control group (Table 3).

A positive change in $\mathrm{HbA}_{1 \mathrm{c}}\left(\mathrm{HbA}_{1 \mathrm{c}}\right.$ reduced) was noted in 50 participants overall (56\% education group, $51 \%$ education and ACT, and $24 \%$ control group).

\subsubsection{Effects on secondary and safety outcomes}

The analyses of the secondary measures are presented in Table 4. No significant differences between the conditions in participants' acceptance of diabetes (AADQ), anxiety and depression, understanding of diabetes, satisfaction with treatment, or satisfaction with blood glucose control. Close to significant between group differences were noted in self-management practices. Self-management activities improved in the education plus ACT group but decreased in the education group to a result reflective of the control group.

Potential adverse events such as episodes of hypoglycaemia were not systematically recorded. Based on episodically reported information, no serious events of hypoglycaemia were recorded in either study group.

TABLE 1 Demographic details

\begin{tabular}{|c|c|c|c|c|c|c|}
\hline \multirow{2}{*}{$\begin{array}{l}\text { Age, mean in } \\
\text { years (SD) } \\
\text { Gender }\end{array}$} & \multicolumn{2}{|c|}{$\begin{array}{c}\text { Education }(\mathrm{N}=34) \\
53.76(8.68)\end{array}$} & \multicolumn{2}{|c|}{$\begin{array}{c}\text { Education \& } A C T(\mathrm{~N}=39) \\
56.1(6.91)\end{array}$} & \multicolumn{2}{|c|}{$\begin{array}{c}\text { Usual Care }(\mathrm{N}=45) \\
56.4(6.97)\end{array}$} \\
\hline & $N$ & $\%$ & $N$ & $\%$ & $\mathrm{~N}$ & $\%$ \\
\hline Male & 20 & 59 & 17 & 44 & 26 & 58 \\
\hline Female & 14 & 41 & 22 & 56 & 19 & 42 \\
\hline \multicolumn{7}{|l|}{ Ethnicity } \\
\hline NZ European & 24 & 71 & 35 & 90 & 36 & 80 \\
\hline \multicolumn{7}{|c|}{ Time since diagnosis } \\
\hline$<5$ years & 13 & 38 & 10 & 26 & 14 & 31 \\
\hline $5-9$ years & 9 & 26 & 14 & 36 & 14 & 31 \\
\hline$>10$ years & 12 & 36 & 15 & 38 & 17 & 38 \\
\hline
\end{tabular}

Abbreviation: ACT, acceptance and commitment therapy. 


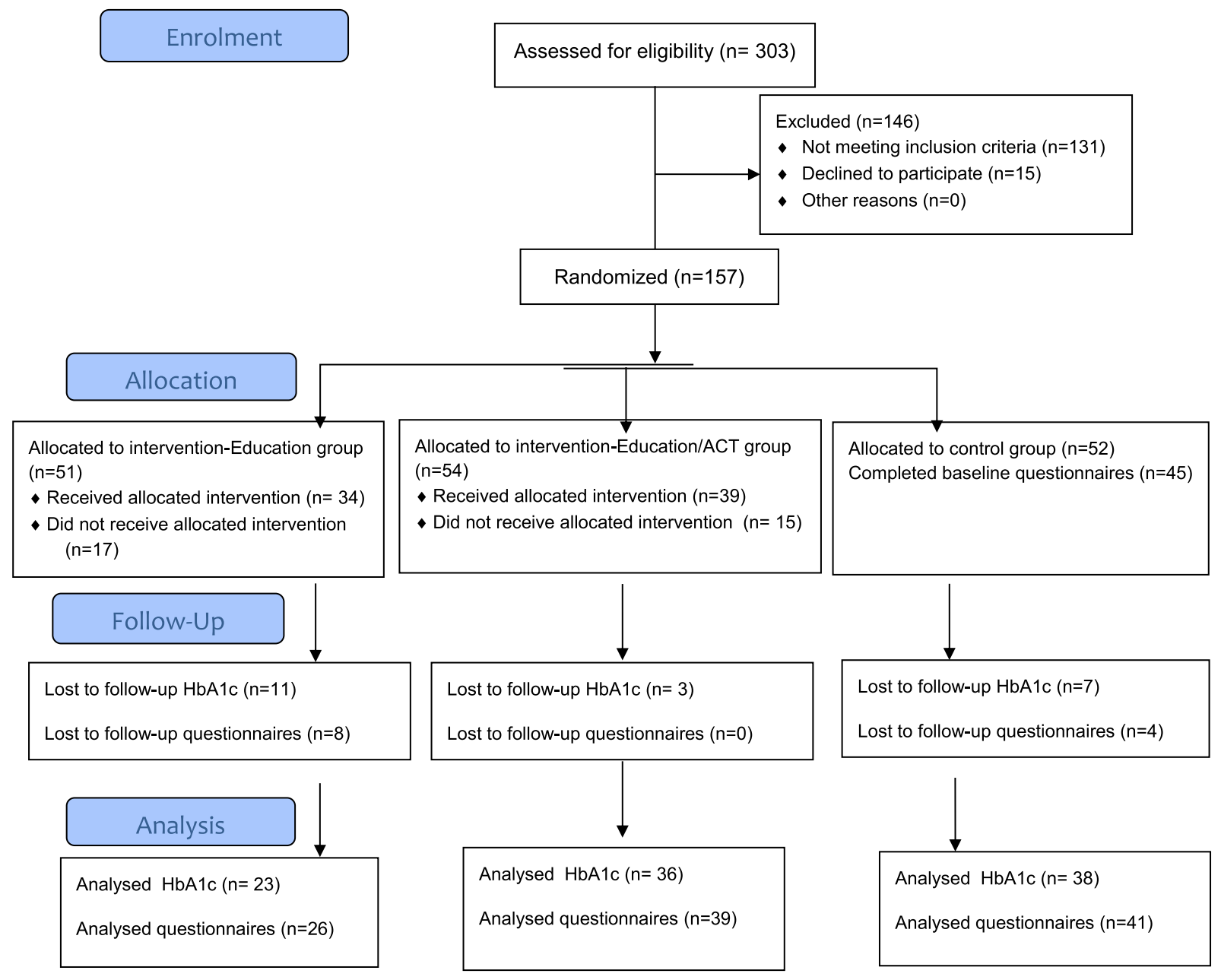

FIGURE 1 Trial profile. ACT, acceptance and commitment therapy; $\mathrm{HbA}_{1 c}$, hemoglobin $\mathrm{A}_{1 \mathrm{c}}$

TABLE 2 HbA1c levels at baseline, 3 months and 6 months

\begin{tabular}{lcccc} 
& Baseline & $\mathbf{3}$ months & $\mathbf{6}$ months & Difference \\
\hline Usual care & 8.08 & 8.13 & 8.40 & +0.32 \\
Education & 8.13 & 7.80 & 7.92 & -0.21 \\
Education + ACT & 7.78 & 7.73 & 7.74 & -0.04 \\
\hline
\end{tabular}

Abbreviations: ACT, acceptance and commitment therapy; $\mathrm{HbA}_{1 \mathrm{c}}$, hemoglobin $A_{1 c}$.

\section{3 | DISCUSSION}

In this study, the $\mathrm{HbA1c}$ level was reduced in both intervention groups and this change was statistically significant in the education only group at 6 months postintervention. No effects on secondary outcomes were found. The results of this study indicate that a 1 day nurse-led group intervention can have an impact on diabetes management up to 6 months postintervention. An earlier study ${ }^{13}$ found a significant decrease in $\mathrm{HbA}_{1 \mathrm{c}}$ in an education plus $\mathrm{ACT}$ group and a significant change (improvement) in acceptance of diabetes as measured by the AADQ and in self-management. In this study, no significant changes on any variable were noted for the education plus ACT group as compared to the control group or education only group. Although the current study did not seek to replicate the Gregg et al study, we did use similar principles and material in developing the intervention. A
TABLE 3 Direction of change in HbA1c

\begin{tabular}{lcccc} 
& \multicolumn{4}{c}{ Direction of change } \\
\cline { 2 - 5 } & Positive N (\%) & None N (\%) & Negative N (\%) & Total \\
\hline Control & $11(24)$ & $4(9)$ & $30(67)$ & 45 \\
Education & $19(56)$ & $2(6)$ & $13(38)$ & 34 \\
Education + ACT & $20(51)$ & $1(3)$ & $18(46)$ & 39 \\
& 50 & 7 & 61 & 118
\end{tabular}

Abbreviations: ACT, acceptance and commitment therapy; $\mathrm{HbA}_{1 \mathrm{c}}$, hemoglobin $A_{1 c}$.

difference in the characteristics of participants by mean years since diagnosis was noted between the studies, 5.3 years ${ }^{13}$ vs 10.03 years in the current study. It could be hypothesised that the difference in outcome between the studies was related to time since diagnosis and that this influenced the ability to change attitudes and values towards diabetes. The potential impact of time since diagnosis on study design and outcome requires further consideration.

In the interventions in this study, and especially so in the education plus ACT group, participants were asked to deal with attitudes towards diabetes and self-care, to observe negative feelings and to reflect on values in life. While this could be challenging and result in increased worry and anxiety about life and diabetes, participants showed stable or improved scores on all psychological variables. 
TABLE 4 Effects on secondary outcome measures

\begin{tabular}{|c|c|c|c|c|c|c|c|c|}
\hline & \multicolumn{3}{|c|}{ Pretreatment } & \multicolumn{5}{|c|}{ Posttreatment (6 months follow-up) } \\
\hline & M & SD & $95 \% \mathrm{Cl}$ & M & SD & Intragroup difference & $95 \% \mathrm{Cl}$ & $\begin{array}{c}\text { F-test (ANCOVA } \\
\text { between groups effects) }\end{array}$ \\
\hline \multicolumn{9}{|c|}{ Acceptance of diabetes } \\
\hline Usual care & 67.8 & 32.02 & $56.17-79.70$ & 70.53 & 33.36 & -1.34 & $63.10-77.26$ & $P<.21$ \\
\hline Education & 71.76 & 28.77 & $56.64-81.26$ & 76.42 & 32.97 & -4.66 & 69.19-84.75 & \\
\hline Education $+\mathrm{ACT}$ & 68.03 & 28.17 & $58.08-85.61$ & 69.03 & 27.54 & -1 & $59.36-75.56$ & \\
\hline Usual care & 5.6 & 4.57 & $4.35-7.31$ & 5.59 & 4.9 & 0.01 & 4.04-7.13 & $P<.98$ \\
\hline Education & 4.62 & 4.13 & $2.98-6.48$ & 4.81 & 3.82 & -0.19 & $3.27-6.35$ & \\
\hline Education + ACT & 5.5 & 3.64 & $4.30-6.70$ & 5.54 & 3.66 & -0.04 & $4.24-6.65$ & \\
\hline \multicolumn{9}{|l|}{ Depression } \\
\hline Usual care & 4.1 & 3.6 & $3.23-5.55$ & 3.49 & 3.01 & 0.61 & $2.64-3.72$ & $p<.95$ \\
\hline Usual care & 3.4 & 1.31 & $2.92-4.10$ & 3.7 & 1.72 & -.03 & $3.15-3.94$ & $P<.53$ \\
\hline Education & 3.09 & 0.72 & $2.75-3.40$ & 4.06 & 1.68 & -0.97 & $3.50-4.40$ & \\
\hline Education + ACT & 3.13 & 0.78 & $2.85-3.50$ & 4.03 & 1.23 & -0.9 & $3.68-4.53$ & \\
\hline \multicolumn{9}{|l|}{ DTSQ-satisfaction } \\
\hline Usual care & 13.13 & 2.95 & $24.37-28.69$ & 6.83 & 6.71 & -6.21 & $6.47-11.24$ & $P<.60$ \\
\hline Education & 12.13 & 4.5 & $20.03-28.47$ & 8.12 & 8.78 & -4.62 & $7.15-12.72$ & \\
\hline Education + ACT & 13.67 & 3.16 & $24.80-29.90$ & 8.85 & 5.13 & -5.57 & $6.26-11.47$ & \\
\hline \multicolumn{9}{|c|}{ DTSQ-blood glucose control } \\
\hline Usual care & .94 & 1.21 & $3.12-4.88$ & .41 & 2.06 & 1.45 & $-.039-1.22$ & $P<.48$ \\
\hline
\end{tabular}

Abbreviations: ACT, acceptance and commitment therapy; ANCOVA, analysis of covariance; Cl, confidence interval; DTSQ, Diabetes Treatment Satisfaction Questionnaire.

Any intervention seeking to reduce $\mathrm{HbA}_{1 \mathrm{c}}$ levels raises concern around increase of hypoglycaemic episodes. In this study, there was no evidence that participants experienced episodes of hypoglyacaemia and no reports of a medical emergency related to hypoglycaemia, although we did not specifically collect data on blood glucose levels outside of the primary measure of $\mathrm{HbA}_{1 \mathrm{c}}$ nor did we directly seek feedback on experiences of hypoglycaemia nor of fear of hypoglycaemia.

Both individual and group settings have been used for cognitivebehavioural interventions, with no definitive conclusion as to which setting is more effective. ${ }^{26,27}$ The literature on educational interventions for diabetes self-management favours the group setting, ${ }^{28}$ although the specific aspects of group intervention that are effective have not been isolated. It is unclear how the group process contributed to outcomes, and this requires further investigation.

The delivery of interventions in a group setting has obvious cost advantages in the clinical setting. This study has also shown that a nurse-led intervention is effective in reducing $\mathrm{HbA}_{1 \mathrm{c}}$. The nurses in this study did not receive costly training and although specialists provided oversight, they did not contribute to the intervention. These findings are of significance in the clinical setting where the ability to draw on staff involved in the regular care of the patient in the primary care setting is both cost-effective and more realistic in embedding interventions into clinical practice. What is not known is whether the input of specialists or of peer leadership would have been more effective and remains an area for future exploration.

It is unclear how long the positive effects of the interventions on glycaemic control observed in this study will last. Taylor et al $^{9}$ noted diminished effects at 12 months and beyond amongst intervention studies to improve self-management of type 2 diabetes. Based on earlier literature, it is likely that maintenance sessions would be required to sustain the effect shown. ${ }^{29}$ Connecting with community partners and other chronic care model programmes running in the community has proven to be a successful adjunct to cognitive-behavioural interventions, allowing the effects to be sustained as far out as 3 years postintervention. ${ }^{24,30,31}$ Incorporating booster sessions enhances the effectiveness of self-management interventions, however, health care providers are challenged in providing continued self-management support over time and as needed by individuals. Reaching patients between visits and tailoring information and support to meet specific needs could be addressed more successfully through the use of technology 
(eg, the Internet, web-based education, text messaging, email, automatic telephone reminders, and telehealth/telephone education and reinforcement). Although the evidence on the effectiveness of e-health is mixed, it is gathering momentum and has been proven effective in the management of $\mathrm{HbA}_{1 \mathrm{c}}$ (eg, in other studies ${ }^{25,32}$ ) and offers a time-efficient means of providing ongoing support.

In summary, the nurse-led education intervention is a promising approach in improving outcomes for those with type 2 diabetes and long-term, less than optimal glycaemic control. Further research to explore the value of group sessions over individual interventions, the relative benefits of ACT versus education, the impact of maintenance sessions, and follow-up over a longer time period would enhance understanding of the value and role of interventions to support glycaemic control.

\section{ACKNOWLEDGEMENTS}

L.W. wrote the manuscript and researched data. M.C., J.C., V.M., D.C., C.B., and C.F. contributed to the design and conduct of the study, analysis of data, and write-up. The study was funded by the Strategy to Advance Research in Nursing and Allied Health (STAR). The funder did not play any role in the conduct of the study.

\section{CONFLICT OF INTEREST}

The authors declare no conflict of interest.

\section{REFERENCES}

1. Peyrot M, Burns KK, Davies M, et al. Diabetes attitudes wishes and needs 2 (DAWN2): a multinational, multi-stakeholder study of psychosocial issues in diabetes and person-centred diabetes care. Diabetes Res Clin Pr. 2013;99:2,174-2,184.

2. NICE (2015) Type 2 diabetes in adults: management. Available from http://www.nice.org.uk/guidance/ng28, Accessed January 7, $2016 .$.

3. Wilkinson A, Whitehead L, Ritchie L. Factors influencing the ability to self-manage diabetes for adults living with type 1 or 2 diabetes. Int $J$ Nurs Stud. 2011;51(1):111-122.

4. World Health Organisation. Causes of death 2008. Data sources and methods. Geneva 2010. Available from http://www.who.int/ healthinfo/global_burden_disease/cod_2008_sources_methods.pdf Accessed January 15, 2016.

5. D'Elia JA, Bayliss G, Roshan B, Maski M, Gleason RE, Weinrauch LA. Diabetic microvascular complications: possible targets for improved macrovascular outcomes. Int J Nephrol Renovasc Dis. 2011;4:1-15.

6. Bejan-Angoulvant T, Cornu C, Archambault P, et al. Is HbA1c a valid surrogate for macrovascular and microvascular complications in type 2 diabetes? Diabetes Metab. 2015;41(3):195-201. https://doi.org/ 10.1016/j.diabet.2015.04.001

7. Buehler AM, Cavalcanti AB, Berwanger $O$, et al. Effect of tight blood glucose control versus conventional control in patients with type 2 diabetes mellitus: a systematic review with meta-analysis of randomized controlled trials. Cardiovasc Ther. 2013 Jun;31(3):147-160. https://doi org/10.1111/j.1755-5922.2011.00308.x

8. IDF (2012) Global guideline for type 2 diabetes management. Available from http://www.idf.org/sites/default/files/IDF-Guideline-for-Type-2Diabetes.pdf, Accessed January 7, 2016.

9. Taylor SJC, Pinnock H, Epiphaniou E, Pearce G, Parke HL, Schwappach A, Purushotham N, Jacob S, Griffiths CJ, Greenhalgh T, Sheikh A. A Rapid Synthesis of the Evidence on Interventions Supporting Self-management for People with Long-term Conditions: PRISMS-Practical Systematic Review of Self-management Support for Long-term Conditions. Southampton (UK): NIHR Journals Library; 2014 Dec.
10. Jones A, Gladstone BP, Lübeck M, Lindekilde N, Upton D, Vach W. Motivationalinterventions in the management of HbA1c levels: a systematic review and meta-analysis. Prim Care Diabetes. 2014;8(2):91-100. https://doi.org/10.1016/j.pcd.2014.01.009

11. Health Quality Ontario. Behavioural interventions for type 2 diabetes: an evidence-based analysis. Ont Health Technol Assess Ser. 2009;9(21):1-45.

12. Hayes SC, Luoma J, Bond F, Masuda A, Lillis J. Acceptance and commitment therapy: model, processes, and outcomes. Behaviour Res Ther. 2006;44:1-25.

13. Gregg J, Callaghan G, Hayes S, Glenn-Lawson J. Improving diabetes self-management through acceptance, mindfulness, and values: a randomized controlled trial. J Consult Clin Psychol. 2007;75(2):336-343.

14. Hayes AJ, Leal J, Gray AM, Holman RR, Clarke PM. UKPDS outcomes model 2: a new version of a model to simulate lifetime health outcomes of patients with type 2 diabetes mellitus using data from the 30 year United Kingdom prospective diabetes study: UKPDS 82. Diabetologia. 2013;56:1925-1933.

15. The DESMOND collaborative, 2008. Available from http://www. desmond-project.org.uk/index.php, Accessed June 13, 2015.

16. Zigmond AS, Snaith RP. The Hospital Anxiety and Depression Scale. Acta Psychiatr Scand. June 1983;67(6):361-370.

17. Bjelland I, Dahl AA, Haug TT, Neckelmann D. The validity of the Hospital Anxiety and Depression Scale. An updated literature review. J Psychosom Res. 2002;52(2):69-77.

18. Spinhoven P, Ormel J, Sloekers PP, Kempen GI, Speckens AE, Van Hemert AM. A validation study of the Hospital Anxiety and Depression Scale (HADS) in different groups of Dutch subjects. Psychol Med. 1997;27(2):363-370

19. Fitzgerald JT, Davis WK, Connell CM, Hess GE, Funnell MM, Hiss RG. Development and validation of the Diabetes Care Profile. Evaluation of Health Professions. 1996;19:208-230.

20. Bradley C. Diabetes treatment satisfaction questionnaire. In: Bradley C ed. Handbook of Psychology and Diabetes. Chur, Switzerland: Harwood Academic Publishers; 1994.

21. Bradley C. The Diabetes Treatment Satisfaction Questionnaire (DTSQ): change version for use alongside status version provides appropriate solution where ceiling effects occur. Diabetes Care. 1999;22(3):530-532

22. Bradley C, Gamsu DS. Guidelines for encouraging psychological wellbeing. Report of a Working Group of the World Health Organization Regional Office for Europe and International Diabetes Federation European Region St Vincent Declaration Action Programme for Diabetes. Diabet Med. 1994;11(5):510-516. https://doi.org/10.1111/j.14645491.1994.tb00316.x

23. Toobert DJ, Glasgow RE, Hampson S. The summary of diabetes selfcare activities measure: results from seven studies and a revised scale. Diabetes Care. 2002;23:943-950.

24. Kim M, Han H, Song H. A community-based, culturally tailored behavioral intervention for Korean Americans with type 2 diabetes. Diabetes Educ. 2009;35:986-994.

25. Hamine S, Gerth-Guyette E, Faulx D, Green B, Ginsburg A. Impact of mHealth chronic disease management on treatment adherence and patient outcomes: a systematic review. J Med Internet Res. 2015;17(2):e52

26. Fan L, Sidani S. Effectiveness of diabetes self-management education intervention elements: a meta-analysis. Canadian Journal of Diabetes. 2009;33(1):18-26

27. Kulzer B, Hermanns N, Reinecker H, Haak T. Effects of self-management training in type 2 diabetes: a randomized, prospective trial. Diabet Med. 2007. https://doi.org/10.1111/j.1464-5491.2007.02089.x

28. Anderson RM, Funnell MM, Nwankwo R, Gillard ML, Oh M, Fitzgerald JT. Evaluating a problem-based empowerment program for African Americans with diabetes: results of a randomized controlled trial. Ethn Dis 2005; 15: 4, 671-678. 
29. Canadian Diabetes Association. Self-management Education. Available from http://guidelines.diabetes.ca/Browse/Chapter7. Accessed June 11, 2015

30. Piatt GA, Anderson RM, Brooks MM, et al. 3-year follow-up of clinical and behavioral improvements following a multifaceted diabetes care intervention: results of a randomized controlled trial. Diabetes Educ. 2010;36:301-309.

31. Gambling T, Long AF. The realisation of patient-centred care during a 3year proactive telephone counselling self-care intervention for diabetes. Patient Educ Couns. 2010;80(2):219-226. https://doi.org/ 10.1016/j.pec.2009.11.007 Epub 2009 Dec 16
32. Kirwan M, Vandelanotte C, Fenning A, Duncan M. Diabetes self-management smartphone application for adults with type 1 diabetes: randomized controlled trial. J Med Internet Res. 2013;15(11):e235.

How to cite this article: Whitehead LC, Crowe MT, Carter JD et al. A nurse-led education and cognitive behaviour therapybased intervention among adults with uncontrolled type 2 diabetes: A randomised controlled trial. J Eval Clin Pract. 2017. https://doi.org/10.1111/jep.12725 